\title{
Usage and perceptions of phosphodiesterase type 5 inhibitors among the male partners of infertile couples
}

\author{
Seung-Hun Song ', Dong Suk Kim ', Sung Han Shim², Jung Jin Lim ${ }^{3,4,5}$, Seung Choul Yang' \\ 'Department of Urology, Fertility Center of CHA Gangnam Medical Center, CHA University, Seoul; ${ }^{2}$ Department of Genetics, CHA University, Seoul, \\ Korea; ${ }^{3} \mathrm{Chronic}$ Disease Program, Ottawa Hospital Research Institute, Ottawa; ${ }^{4}$ Department of Obstetrics and Gynecology, University of Ottawa, \\ Ottawa; ${ }^{5}$ Department of Cellular and Molecular Medicine, University of Ottawa, Ottawa, Canada
}

Objective: We aimed to investigate the prevalence of erectile dysfunction (ED) and the usage of phosphodiesterase type 5 (PDE5) inhibitors for ED treatment in infertile couples.

Methods: A total of 260 male partners in couples reporting infertility lasting at least 1 year were included in this study. In addition to an evaluation of infertility, all participants completed the International Index of Erectile Function (IIEF)-5 questionnaire to evaluate their sexual function. The participants were asked about their use of PDE5 inhibitors while trying to conceive during their partner's ovulatory period and about their concerns regarding the risks of PDE5 inhibitor use to any eventual pregnancy and/or the fetus.

Results: Based on the IIEF-5 questionnaire, $41.5 \%$ of the participants (108/260) were classified as having mild ED (an IIEF-5 score of 17-21), while $10.4 \%$ of the participants (27/260) had greater than mild ED (an IIEF-5 score of 16 or less). The majority $(74.2 \%, 193 / 260)$ of male partners of infertile couples had a negative perception of the safety of using a PDE5 inhibitor while trying to conceive. Only $11.1 \%$ of men (15/135) with ED in infertile couples had used a PDE5 inhibitor when attempting conception.

Conclusion: ED was found to be common in the male partners of infertile couples, but the use of PDE5 inhibitors among these men was found to be very low. The majority of male partners were concerned about the risks of using PDE5 inhibitors when attempting to conceive. Appropriate counseling about this topic and treatment when necessary would likely be beneficial to infertile couples in which the male partner has ED.

Keywords: Erectile dysfunction; Infertility; Phosphodiesterase 5 inhibitor

\section{Introduction}

Infertility, with a prevalence of $10 \%$ to $15 \%$, is a major issue in many

Received: Oct 30, 2015 · Revised: Dec 12, 2015 · Accepted: Jan 15, 2016 Corresponding author: Seung-Hun Song

Department of Urology, Fertility Center of CHA Gangnam Medical Center, CHA University, 566 Nonhyeon-ro, Gangnam-gu, Seoul 06135, Korea

Tel: +82-2-3468-3413 Fax:+82-2-3468-3449 E-mail: shsong02@cha.ac.kr

* This research was supported by a grant of the Korea Health Technology R\&D Project through the Korea Health Industry Development Institute (KHIDI), funded by the Ministry of Health \& Welfare, Republic of Korea (grant number: HI14C0106020014).

This is an Open Access article distributed under the terms of the Creative Commons Attribution Non-Commercial License (http://creativecommons.org/licenses/by-nc/3.0/) which permits unrestricted non-commercial use, distribution, and reproduction in any medium, provided the original work is properly cited. societies [1]. Infertility is defined as the failure to conceive after at least 12 consecutive months of unprotected sexual intercourse. Normal male sexual function is necessary for successful sexual performance and the chance of pregnancy. Previous reports, however, have found that the male partners of infertile couples commonly experience increased sexual stress related to infertility, report lower levels of sexual satisfaction, and exhibit a significantly increased risk of erectile dysfunction (ED) [2-4]. The recent social trend of late marriage may also be a contributing factor to the high incidence of sexual dysfunction among the male partners of infertile couples. The proper management of sexual dysfunction in these men is an important issue, both for the male partner and the infertile couple.

Phosphodiesterase type 5 (PDE5) inhibitors are the current phar- 
maceutical treatment of choice for ED. PDE5 inhibitors were first introduced primarily for elderly men with the launch of sildenafil citrate in March 1998, followed by the introduction of vardenafil and tadalafil $[5,6]$. These PDE5 inhibitors have been shown to be very effective in improving male erectile function and they are now very popular throughout the world [7]. With their tremendous success as a pharmaceutical treatment of ED, marketing strategies have extended to include younger men. Recent reports of the recreational use of PDE5 inhibitors by healthy young men show the popularity of these drugs [8]. Therefore, considering the common incidence of male sexual problems in couples with fertility issues and the increased accessibility of PDE5 inhibitors, the chances of PDE5 inhibitor usage among male partners of infertile couples have increased.

Unfortunately, no data exist regarding the use of PDE5 inhibitors among the male partners of infertile couples. Information about the prevalence of ED and the usage of PDE5 inhibitors among the male partners of infertile couples could provide data relevant to the clinical treatment of infertile couples. In this study, we investigated the prevalence of ED and the usage of PDE5 inhibitors for ED treatment among infertile couples.

\section{Methods}

This study included the male partners of couples who sought medical treatment or a clinical evaluation between February 1, 2014 and November 30, 2014 for infertility lasting at least 1 year. The study was approved by CHA Gangnam Medical Center, CHA University. All participants underwent a comprehensive interview, physical examination, semen analysis, and/or a hormonal profile study. Patients with

Table 1. Baseline characteristics of patients

\begin{tabular}{lccc}
\hline Characteristic & $\begin{array}{c}\text { Men without } \\
\text { PDE5 inhibitors } \\
(\mathrm{n}=245)\end{array}$ & $\begin{array}{c}\text { Men with } \\
\text { PDE5 inhibitors } \\
(\mathrm{n}=15)\end{array}$ & $p$-value ${ }^{\mathrm{a})}$ \\
\hline Age $(\mathrm{yr})$ & $37.1(32-42)$ & $39.4(35-44)$ & $\mathrm{NS}$ \\
Infertility duration $(\mathrm{mo})$ & $18 \pm 3.5$ & $21 \pm 4.3$ & 0.017 \\
Serum FSH $(\mathrm{mlU} / \mathrm{mL})$ & $4.7 \pm 2.1$ & $5.2 \pm 3.4$ & $\mathrm{NS}$ \\
Serum testosterone $(\mathrm{ng} / \mathrm{dL})$ & $525.2 \pm 118.2$ & $432.2 \pm 109.2$ & 0.005 \\
Testis size $(\mathrm{mL})$ & & & \\
$\quad$ Right & $15.4 \pm 2.7$ & $14.8 \pm 3.2$ & $\mathrm{NS}$ \\
$\quad$ Left & $15.1 \pm 3.6$ & $14.6 \pm 2.1$ & $\mathrm{NS}$ \\
Sperm parameters & & & \\
$\quad$ Concentration $\left(\times 10^{6} / \mathrm{mL}\right)$ & $80.3 \pm 48.1$ & $69.3 \pm 45.2$ & $\mathrm{NS}$ \\
$\quad$ Motility $(\%)$ & $41.1 \pm 11.4$ & $43.1 \pm 16.2$ & $\mathrm{NS}$ \\
$\quad$ Morphology $(\%)$ & $5.4 \pm 1.5$ & $4.9 \pm 1.5$ & $\mathrm{NS}$ \\
\hline
\end{tabular}

Values are presented as mean (range) or mean \pm standard deviation. PDE5, phosphodiesterase type 5; NS, not significant; FSH, follicle stimulating hormone.

a) Statistical significances were tested by Mann-Whitney U test. underlying chronic medical conditions such as diabetes, hypertension, or severe male infertility issues, such as azoospermia or hypogonadism, were excluded.

The basic fertility tests included a semen analysis and a reproductive hormonal analysis. Samples were obtained for semen analysis by masturbation after 2 to 7 days of sexual abstinence. After liquefaction of the semen samples, standard semen parameters (volume, concentration, motility, and morphology) were obtained according to the 2010 World Health Organization guidelines [9].

All participants completed the International Index of Erectile Function (IIEF)-5 questionnaire to evaluate their sexual function. Their scores were interpreted as follows: severe ED, 5-7; moderate ED, 8-11; mild to moderate ED, 12-16; mild ED, 17-21; no ED, 22-25 [10]. The participants were asked about their use of PDE5 inhibitors while trying to conceive during their partner's ovulatory period and about their concerns regarding the potential risks to any eventual pregnancy and/or the fetus. The degree of their concern about risk to the pregnancy or fetus was classified as high, intermediate, low, or none. Statistical analyses were performed using SPSS ver. 21 (IBM Co., Armonk, NY, USA). The variables were reported as mean \pm standard deviation or as frequency distributions.

\section{Results}

A total of 260 healthy male partners of infertile couples were included in this study. The patients' characteristics are summarized in Table 1. The duration of infertility and serum testosterone levels were significantly different depending on PDE5 inhibitor use. An analysis of the IIEF- 5 scores of the participants demonstrated that $48.1 \%$ $(125 / 260)$ had no ED (an IIEF-5 score of 22-25). The prevalence of mild ED (an IIEF-5 score of 17-21) was $41.5 \%$ (108/260), and the prevalence of more than mild ED (an IIEF- 5 score of 16 or less) was

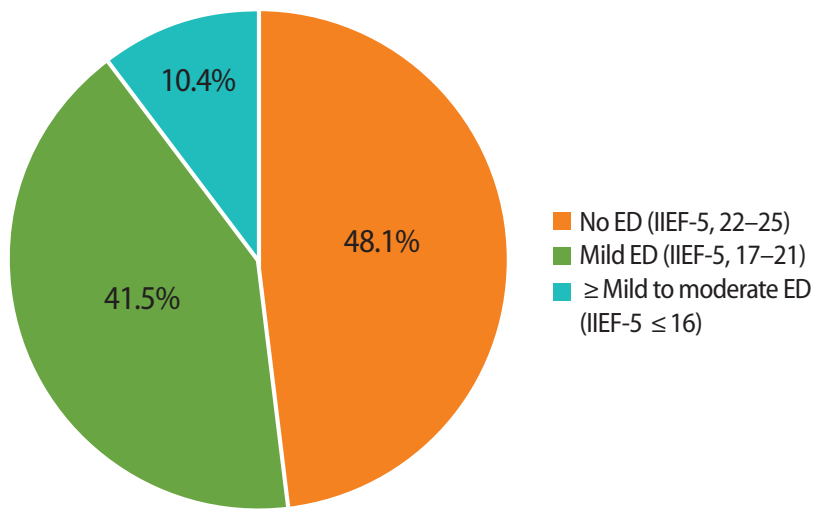

Figure 1. The prevalence of erectile dysfunction (ED) among the male partners of infertile couples. IIEF, International Index of Erectile Function. 


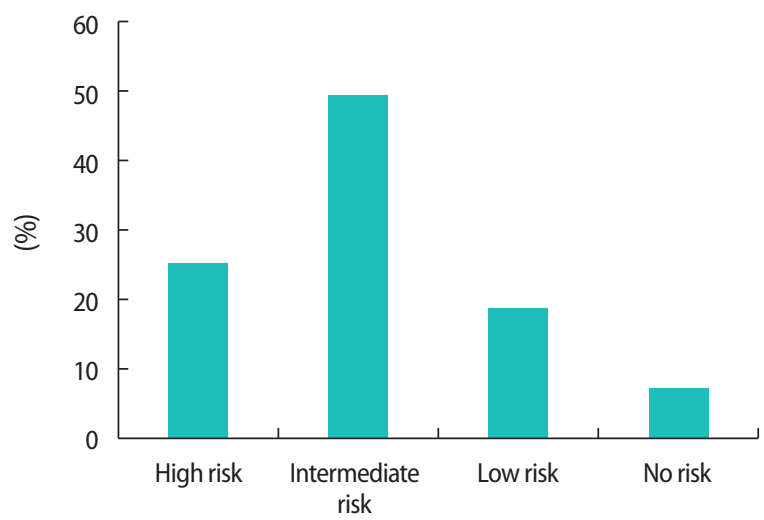

Figure 2. Concerns articulated by male partners about the safety of phosphodiesterase- 5 inhibitors regarding risks to a pregnancy and/ or fetus during the female partner's ovulatory period.

\section{4\% (27/260) (Figure 1).}

Answers to the question about the perceived safety of PDE5 inhibitors during attempts to conceive were divided into four groups: high risk, 25.0\% (65/260); intermediate risk, 49.2\% (128/260); low risk, $18.8 \%$ (49/260); and no risk, $6.9 \%$ (18/260) (Figure 2).

Only $11.1 \%(15 / 135)$ of the men with ED in infertile couples had used a PDE5 inhibitor when attempting to conceive. Three of those men (20.0\%) had mild ED, and 12 (80.0\%) had more than mild ED. Five (33.3\%) experienced mild headache and facial flushing related to the use of a PDE5 inhibitor.

\section{Discussion}

This is the first study to investigate the usage of PDE5 inhibitors by the male partners of infertile couples. The success of PDE5 inhibitors in treating ED and their increased accessibility have increased their usage among men of reproductive age [11,12]. However, our study showed that the prevalence of PDE5 inhibitor usage among the male partners of infertile couples was very low. In our study, only $11.1 \%$ (15/135) of men with ED had used a PDE5 inhibitor while their partner was trying to conceive. This low usage rate of PDE5 inhibitors may have been partially due to the fact that the severity of ED in these relatively young men was mostly mild and their ED was generally psychogenic, meaning that the necessity for medical treatment was not great. Moreover, interestingly, the majority of male partners of infertile couples had a negative perception of the safety of using a PDE5 inhibitor when their partners were in a near-fertile or ovulatory period. Approximately $74 \%$ of the participants (193/260) believed that the usage of a PDE5 inhibitor during the fertile window period would be risky (high risk or intermediate risk). Only $25.8 \%$ of participants $(67 / 260)$ replied that the usage of a PDE5 inhibitor when attempting to conceive would generally be safe (low risk or no risk).
This finding emphasizes the importance of conveying accurate information about PDE5 inhibitors and properly counseling male partners with ED in infertile couples.

PDE5 inhibitors are generally safe. They are infrequently associated with adverse events and so far, toxicity tests have shown no known effects on fertility. However, the local effects of PDE5 inhibitors on sperm and the fertilization process have not been studied thoroughly, partly because studies of PDE5 inhibitors have primarily been focused on their contribution to sexual satisfaction, mainly in elderly men. PDE5 inhibitors act by blocking the degradative action of PDE5 in the corpus cavernosum of the penis. However, other isoforms of phosphodiesterase enzymes have been found to exist in sperm cells, suggesting that PDE5 inhibitors may influence sperm cell function [13]. Some reports have described the influence of PDE5 inhibitors on various sperm cell functions $[14,15]$. One study reported that concentrations of $0.1-0.3 \mathrm{~mol} / \mathrm{L}$ in the ejaculate, resulting from the acute oral administration of $100 \mathrm{mg}$ of sildenafil citrate, could have possible inhibitory effects on the actions of sperm PDE isoforms [16]. Another study suggested that PDE5 inhibitors could have a negative effect on male fertility by causing premature acrosome reaction [17]. Although studies have reported conflicting results about the influence of PDE5 inhibitors on sperm function, these data suggest the necessity of obtaining more reliable data about safety aspects related to the use of PDE5 inhibitors and fertilization process $[18,19]$. This is an especially important issue since the daily use of a PDE5 inhibitor has become a widespread regimen. The on-demand usage of PDE5 inhibitors means that the exposure of sperm cells or the male reproductive system to PDE5 inhibitors is short, thereby minimizing the likelihood of potentially adverse effects. However, with daily use, the PDE5 inhibitor would consistently be present in the plasma and other parts of the male reproductive tract, such as the epididymis, during the full spermatogenic process. Therefore, a long-term effect on sperm function and the fertilization process is possible, and the potential side effects of daily usage should be thoroughly evaluated.

PDE5 inhibitors may be useful for treating ED in the male partners of infertile couples. Some reports have demonstrated the usefulness of PDE5 inhibitors during infertility treatment in clinical settings [20]. When undergoing assisted reproduction techniques such as intrauterine insemination, men with ED sometimes have difficulties producing a semen sample on demand. Although such instances of ED are usually stress-induced and transitory, PDE5 inhibitors can effectively reverse ED to ensure proper semen collection. Previous studies have shown a significant proportion of the male partners of infertile couples to have decreased sexual function $[2,4]$. The prevalence of more than mild ED (an IIEF-5 score of 16 or less) in our study was $10.4 \%(27 / 260)$, and the prevalence of mild ED (an IIEF-5 of 17-21) was $41.5 \%$ (108/260). Based on these results, we suggest that men 
with ED in infertile couples may be promising candidates for medical treatment.

Several limitations of our study should be noted. First, this study was carried out in East Asia. The prevalence of PDE5 inhibitor usage and concerns about their safety may vary among subject groups with different social and cultural backgrounds. Second, the presence of ED was assessed using the IIEF-5 questionnaire. The data obtained from this questionnaire may be relatively subjective, partially explaining the high prevalence of ED in this population. The majority of cases of ED in these men were likely to be of psychogenic origin rather than organic. Third, although the duration of infertility and serum testosterone levels showed significant differences depending on PDE5 inhibitor usage, this finding should be interpreted with caution due to the small sample size of men who had used PDE5 inhibitors. Fourth, this study investigated the usage of PDE5 inhibitors at the time of the female partner's ovulatory period. Despite the limitations, this is the first study to investigate PDE5 inhibitor usage in the male partners of infertile couples. In addition, our results suggest that it is necessary to obtain reliable data regarding the long-term impact of PDE5 inhibitors on the male reproductive system and the fertilization process. Although PDE5 inhibitors may be effective drugs for treating $\mathrm{ED}$ in the male partners of infertile couples, we strongly suggest that a more thorough investigation is needed regarding potential interactions between PDE5 inhibitors and sperm cells.

In conclusion, erectile dysfunction is common in the male partners of infertile couples, and these young men with ED may be potential candidates for PDE5 inhibitor treatment. However, the prevalence of PDE5 inhibitor usage among these men was found to be very low, and the majority of them were concerned about the risks posed by PDE5 inhibitors during attempts to conceive. Appropriate counseling is needed and thorough studies should be carried out on a wider scale to assess the potential effects of PDE5 inhibitors on the male reproductive system and sperm cell function.

\section{Conflict of interest}

No potential conflict of interest relevant to this article was reported.

\section{References}

1. Kessler LM, Craig BM, Plosker SM, Reed DR, Quinn GP. Infertility evaluation and treatment among women in the United States. Fertil Steril 2013;100:1025-32.

2. Shindel AW, Nelson CJ, Naughton CK, Ohebshalom M, Mulhall JP. Sexual function and quality of life in the male partner of infertile couples: prevalence and correlates of dysfunction. J Urol 2008;179:1056-9.
3. Ramezanzadeh F, Aghssa MM, Jafarabadi M, Zayeri F. Alterations of sexual desire and satisfaction in male partners of infertile couples. Fertil Steril 2006;85:139-43.

4. O'Brien JH, Lazarou S, Deane L, Jarvi K, Zini A. Erectile dysfunction and andropause symptoms in infertile men. J Urol 2005;174: 1932-4.

5. Boolell M, Gepi-Attee S, Gingell JC, Allen MJ. Sildenafil, a novel effective oral therapy for male erectile dysfunction. Br J Urol 1996;78:257-61.

6. Kalsi JS, Bahadur G, Muneer A, Ozturk O, Christopher N, Ralph DJ, et al. Novel PDE5 inhibitors for the treatment of male erectile dysfunction. Reprod Biomed Online 2003;7:456-61.

7. Park HJ, Moon KH, Lee SW, Lee WK, Kam SC, Lee JH, et al. Mirodenafil for the treatment of erectile dysfunction: a systematic review of the literature. World J Mens Health 2014;32:18-27.

8. Bechara A, Casabe A, De Bonis W, Helien A, Bertolino MV. Recreational use of phosphodiesterase type 5 inhibitors by healthy young men. J Sex Med 2010;7:3736-42.

9. World Health Organization. WHO laboratory manual for the examination and processing of human semen. 5th ed. Geneva: World Health Organization; 2010.

10. Rhoden EL, Teloken C, Sogari PR, Vargas Souto CA. The use of the simplified International Index of Erectile Function (IIEF-5) as a diagnostic tool to study the prevalence of erectile dysfunction. Int J Impot Res 2002;14:245-50.

11. Peters RJ Jr, Johnson RJ, Kelder S, Meshack AF, Jefferson T. Beliefs and social norms about sildenafil citrate (Viagra) misuse and perceived consequences among Houstonian teenage males. Am J Mens Health 2007;1:208-12.

12. Smith KM, Romanelli F. Recreational use and misuse of phosphodiesterase 5 inhibitors. J Am Pharm Assoc (2003) 2005;45:6372.

13. Fisch JD, Behr B, Conti M. Enhancement of motility and acrosome reaction in human spermatozoa: differential activation by type-specific phosphodiesterase inhibitors. Hum Reprod 1998; 13:1248-54.

14. Cuadra DL, Chan PJ, Patton WC, Stewart SC, King A. Type 5 phosphodiesterase regulation of human sperm motility. Am J Obstet Gynecol 2000;182:1013-5.

15. Lefievre L, De Lamirande E, Gagnon C. The cyclic GMP-specific phosphodiesterase inhibitor, sildenafil, stimulates human sperm motility and capacitation but not acrosome reaction. J Androl 2000;21:929-37.

16. Fabbri A, Aversa A, Isidori A. Sildenafil and erectile dysfunction. J Endocrinol Invest 1999;22:486-92.

17. Glenn DR, McVicar CM, McClure N, Lewis SE. Sildenafil citrate improves sperm motility but causes a premature acrosome reac- 
tion in vitro. Fertil Steril 2007;87:1064-70.

18. du Plessis SS, de Jongh PS, Franken DR. Effect of acute in vivo sildenafil citrate and in vitro 8-bromo-cGMP treatments on semen parameters and sperm function. Fertil Steril 2004;81:102633.
19. Mostafa T. Oral phosphodiesterase-5 inhibitors and sperm functions. Int J Impot Res 2008;20:530-6.

20. Tur-Kaspa I, Segal S, Moffa F, Massobrio M, Meltzer S. Viagra for temporary erectile dysfunction during treatments with assisted reproductive technologies. Hum Reprod 1999;14:1783-4. 